\title{
Carolina e Clarice: aproximações entre fenomenologia heideggeriana, feminino e literatura
}

\author{
Danielle de Gois Santos Caldeira ${ }^{1}$ (i)
}

Universidade do Porto

\section{Artigos livres | Free articles | Articulos libres DOI do artigo: 10.22481/odeere.v6i01.7870 \\ RESUMO}

A literatura mundial reconhece Carolina de Jesus e Clarice Lispector como escritoras reflexivas e críticas à sociedade brasileira do século XX e ao feminino. Este artigo expõe uma leitura hermenêutica inspirada em Martin Heidegger, a respeito de Quarto de Despejo e Perto do Coração Selvagem, clássico literários, entendendo-os como horizontes de encontro para compreender o feminino desde a circularidade de sentido envolvendo entes humanos e existenciais heideggerianos. A apropriação da linguagem das escritoras estreou modos de libertação do feminino, desvelamentos de significados e concepções de mundo. Expor a Fenomenologia heideggeriana atenta ao feminino, acrescida da análise psicológica das escritoras, reflete suposta neutralidade histórica, cultural e literária que elege protagonistas-narradores masculinos como singulares, e segregam o feminino a relacionamentos, filiações ou proles. Os resultados, a partir da reflexão/compreensão hermenêutica, reconstroem noção de humanidade que rompe com complementaridades, por exemplo, personagens femininas que não procuram pelo masculino; que explicita noção do eu feminino que não reforça intimismo, a primeira pessoa, nesses clássicos, é uma indeterminação correspondendo aqueles à margem social. As lutas cotidianas sejam contra fome, sejam não sucumbir a acessório do masculino, fazem da hermenêutica do feminino exercício de resistência. Apropriar o humano de sua correspondência com mundo ao formular sentidos não discriminatórios possibilita e empodera o formular de reflexões e ações demonstrativas de liberdade e ética.

Palavras-chave: Fenomenologia Hermenêutica; Martin Heidegger, Feminino, Literatura.

\section{Carolina and Clarice: approximations between Heideggerian phenomenology, femine and literature}

ABSTRACT

World literature recognizes Carolina de Jesus and Clarice Lispector as reflective and critical writers on Braszilian society in the 20 th century ando $\mathrm{n}$ women. This article exposes a hermeneutic Reading inspired by Martin Heidegger, about the Dump Room and Close to the Wild Heart, classic literary, undestanding them as horizons of encounter to undestand the feminine since the circularity of meaning involving Heideggerian human and existential beings. The appropriation of the writers' language debuted ways of liberating the feminine, unveiling meanings and conceptions of the world. Exposing Heidegger's Phenomenology attentive to the female, plus the psychological analysis of the writers, reflexts supposed historical, cultural and literary neutrality that elects male protagonistsnarrators assingular, and segregates the female into relationships, affiliations or offspring. The results, based on hermeneutic reflection/undestanding, reconstruct the notion of humanity that breaks with complementarities, for exemple, female characters who do not look for the male; that makes explicit the notion of the female self that does not not reinforce intimacy, the first person, in these classics, is an indeterminacy corresponding to those of the social margin. The daily struggles against hunger, or not succumbing to male enhancement, make enhancement, make female, hermeneutics an exercise in resistance. Appropriating humans from their correspondence with the world by formulating non-discriminatory meanings enables and empowers the formulation of reflections and actions demonstrating freedom and ethics.

Keywords: Hermeneutic Phenomenology; Martin Heidegger; female; literature.

Submetido em: 23 de dez. de 2020| Aceito em: 19 de mar. de 2021

1 Psicóloga pela Universidade Federal de Sergipe (UFS/Brasil). Doutora em Psicologia pela Universidade Federal do Rio Grande do Norte (UFRN/Brasil). Doutora em Filosofia pela Universidade de Évora (Portugal). Atualmente, desenvolve investigação a nível de pós-doutoramento na Universidade do Porto (Portugal) e atua na clínica em Psicologia a partir da fundamentação Fenomenológica Hermenêutica e Análise Existencial. E-mail: danielledegois.psi@gmail.com 
Primeiramente, quem são Carolina e Clarice referidas no título do artigo?

Iniciar este artigo com esses nomes revela-se uma eleição pelo designar dos nomes próprios das escritoras investigadas, uma tentativa de reconhecimento das literatas e, igualmente, aproximar-nos do feminino presente nas narrativas pesquisadas. Ressalto o risco suscitado quando são eleitos sobrenomes para fazer referência aos autores e aos protagonistas aproximando-os de possíveis indeterminações. Tais indeterminações, usualmente, são envolvidas por características proeminentes na tradição cultural científica que assinalam substantivos próprios remetidos ao simbolismo de pertença ao masculino.

Os femininos apresentados por Carolina Maria de Jesus (1914-1977) e Clarice Lispector (1920-1977) aproximam todos que motivados pela curiosidade, expressão de nossa abertura ao mundo, andarilham por experiências que não são exclusivas das mulheres e, assim, dizem muito da humanidade que somos.

A temática central escolhida é o feminino. Ao mesmo tempo, a perspectiva Fenomenológica Existencial de Martin Heidegger (1889-1976) é introduzida e fundamenta o desvelar do fenômeno do feminino, entendendo-o na qualidade de componente da nossa humanidade. Consoante Martin Heidegger, em Ser e tempo, são fomentadas compreensões quanto à condição ontológica de ser-nomundo, a partir das linguagens desenvolvidas por Carolina de Jesus e Clarice Lispector nos clássicos da literatura brasileira, respectivamente, Quarto de despejo: diário de uma favelada² e Perto do coração selvagem ${ }^{3}$. Estes clássicos nos emprestam os recursos para refletir e propor posicionamentos na direção de uma perspectiva de humanidade coesa em singularidades e empoderamentos.

A obra Quarto de despejo: diário de uma favelada foi publicada em 1960. O clássico reúne o trabalho de Carolina Maria de Jesus que em 1958 teve seu diário pessoal reconhecido pelo jornalista Audálio Dantas como uma obra que precisava ser de conhecimento da população brasileira e mundial. Após 1960, o clássico de Carolina de Jesus alcançou 16 traduções, 46 países e percorre o mundo na atualidade.

\footnotetext{
2 JESUS, 1960/2007.

${ }^{3}$ LISPECTOR,1943/1998.
} 
Caldeira, D. G. S., Carolina e Clarice: aproximações entre fenomenologia heideggeriana, feminino

Perto do coração selvagem foi o romance de estreia de Clarice Lispector. Publicado em dezembro de 1943, o livro revela o estilo introspectivo da escritora e foi premiado como melhor romance de estreia pela Fundação Graça Aranha, em outubro de 1944.

Após introduzir o tema de predileção e indicar a fundamentação inspiradora para reflexões e construção de conhecimento, na interface entre literatura, saberes psicológicos e filosóficos, apresento os quatros caminhos que integram este artigo: I) $\bigcirc$ fenômeno do feminino na literatura de Carolina de Jesus e Clarice Lispector; II) Horizontes que se cruzam: Fenomenologia Hermenêutica heideggeriana, Quarto de despejo: diário de uma favelada e Perto do coração selvagem; III) Escritos de libertação do feminino e IV) Uma Fenomenologia Hermenêutica do feminino como resistência, modo ético de experienciar.

\section{I) O fenômeno do feminino na literatura de Carolina de Jesus e de Clarice Lispector}

Resgatar Quarto de despejo: diário de uma favelada e Perto do coração selvagem foge a qualquer simplificação como quem cita alegorias. A precisão com que essas obras literárias tocam assuntos cotidianos não se reserva a geografia física. Se tivermos de considerar uma geografia que sejam as geografias humanas das relações, as quais são descritas suspendendo o ponto de início ou de fim dos modos de vida ali apresentados. Esses escritos nos acompanham ao longo do dia, no fervilhar de escolhas já realizadas. Inclusivamente, os escritos referidos não caberiam de ser investigados a par de nos preparar para o repouso da noite, pois são escritos provocadores, do gênero que antes mesmo de concluirmos a leitura rapidamente permanecem em nós, revirando 0 que acreditávamos conhecer/dominar.

O feminino não é resgatado como um constructo que foi esquecido/sufocado; não é reavido semelhante uma parte negligenciada; nas literaturas investigadas, o feminino é privilegiado tal e qual faz nascer/despertar resistência e correspondências no/com o mundo.

Conforme Trible4, a própria história do feminino necessita de ser ressaltada no que diz respeito ao enviesamento do patriarcado, contudo isto só é uma porção

4 TRIBLE, 1973. 
da sua história. Escritoras como Carolina de Jesus e Clarice Lispector personificam convite/provocação, possibilitando que mesmo dentro de uma seara de patriarcado existem muitas versões de modos de vida a serem desvelados.

Produtos do patriarcado cristão que reiteradamente dominam, desertificam e vitimizam, sofrem reviravolta possível na junção educação (Literatura) e afetividade promovida pelas escritoras citadas. O desafio de investigar as escritoras desmascara virtudes, responsabilidades e atitudes por elas impressas e que as leio como exercícios de nos mantermos livres e éticos, reformuladores da concepção do humano.

Desconfiar da naturalidade companheira de classificações embasadas em critérios binários comuns nas discussões sobre feminino e masculino é justificativa para o desenvolver deste artigo a partir da Fenomenologia Hermenêutica heideggeriana, visto que não se trata apenas de fazer uma leitura de classificações, e sim compreender e desvelar sentidos que rompem com padrões graças ao seu caráter originalmente crítico. No caso, quanto aos padrões associados aos gêneros masculino e feminino interessa não apenas romper com ideias de disparidades entre eles, não obstante, compor desvios como o de nos mantermos atentos ao que de masculino e feminino fazem sentido em nossas vivências.

$\mathrm{Na}$ atualidade, a concepção antropocêntrica é representada por pressupostos radicais e rígidos. Nessa, ao reunir no homem o centro de entendimento da humanidade e de tudo o que a atravessa, o feminino é distinto como uma impressão nociva, graças à valorização da afetividade e/ou à ameaça que o empoderamento feminino exerce. Neste sentido, as escritoras experimentam falar dos seus lugares questionadas por dúvidas de como seriam as suas vidas e de personagens se não fossem, desde sempre, destituídas para as margens. Chamo atenção para o fato de escritoras e personagens serem interpelados por dúvidas que se assemelham a serem questionadas $e$ inquirirem seus personagens criticamente quanto aos modos como lidam com a vida. A contar com as dúvidas, observo escritoras e personagens num contínuo de tutela à força dos afetos que compõem seus saberes e suas emoções no diálogo com o mundo. O feminino entre escritoras e personagens inclui dúvidas, além de acrescido por doses não 
Caldeira, D. G. S., Carolina e Clarice: aproximações entre fenomenologia heideggeriana, feminino

conformistas quanto às solicitações/exigências a elas (escritoras e personagens) dirigidas.

Em vista das primeiras impressões e posicionamentos aos quais conduzi a apresentação de escritoras e seus escritos, convido os/as leitores/as a percorrer horizontes possíveis, em que convergem femininos cujos atributos versam por perseveranças.

\section{II) Horizontes que se cruzam: Fenomenologia Hermenêutica heideggeriana, Quarto de despejo e Perto do coração selvagem}

Martin Heidegger e sua Fenomenologia são inspirações para a leitura dos clássicos literários referidos. Saliento que o filósofo não foi o único a desenvolver um exercício hermenêutico ao lado do ressaltar de fenômenos expressivos de nossas experiências cotidianas. A propósito, Hans-Georg Gadamer (1990-2002) apresentou em Gadamer 5 (1997) hermenêutica enquanto maneira de aceder à compreensão da experiência. O testemunho presente nas obras do filósofo Heidegger continua propositivo pela não valorização de hierarquias entre compreender e interpretar, admitindo compreender e interpretar como experiências coexistentes. O exercício hermenêutico valoriza experiências, o que dialoga com interesses de produção de conhecimento atento à investigação e à promoção das relações humanas. Neste artigo, o exercício fenomenológico hermenêutico heideggeriano presente em sua Fenomenologia Existencial mobiliza leituras interessadas na compreensão de situar nos clássicos literários a importância do existir, tendo em vista a promoção de humanos críticos e inventivos em relação à correspondência humano-mundo.

Usualmente, nas ciências, o caráter interpretativo tendo em vista explicações, conceituações e definições, é privilegiado em detrimento da compreensão. Todavia, resgatar a Hermenêutica para as ciências e para o cotidiano transforma experiências que seriam qualificadas como corriqueiras e insignificantes em expressões manifestas de sentido. Nesta investigação a Fenomenologia Hermenêutica heideggeriana percorre caminhos conciliadores, nos quais

5 GADAMER, 1997. 
Caldeira, D. G. S., Carolina e Clarice: aproximações entre fenomenologia heideggeriana, feminino

compreender/interpretar o feminino colabora para o incentivo a nos tornarmos cada vez mais humanos.

A proposição de uma compreensão Fenomenológica Hermenêutica heideggeriana nos clássicos literários não substitui leituras sob outras perspectivas. Por sua vez, trata-se de admitir o fenômeno do feminino em diálogo com leitores, em seu contexto de vida fáctica. A expressão vida fáctica deriva do modo próprio de ser da existência, segundo o filósofo:

O conceito de facticidade abriga em si o ser-no-mundo de um ente "intramundano", de maneira que esse ente possa ser compreendido como algo que, em seu "destino", está ligado ao dos entes que lhes veem ao encontro dentro do seu próprio mundob).

Ao investigar o fenômeno do feminino apresento alguns elementos constitutivos que o associam aos existenciais heideggerianos; manejos de linguagem das escritoras que mais parecem artifícios para destacar o não óbvio, uma vez que abordam o cotidiano de quem precisa se interpelar quanto ao seu lugar no mundo, na medida em que luta pelo direito de compor a humanidade.

Ao privilegiar as experiências, a Fenomenologia Hermenêutica acede ao cotidiano destacando o ente humano inserido no seu horizonte. Isto pode ser demonstrado através de personagens criadas e autorretratadas pelas escritoras. As personagens compartilham as sensiveis compreensões/interpretações de suas histórias ao passo que transitam por seus percursos. Outro destaque que associo à Fenomenologia Hermenêutica heideggeriana é o fator mudança. Igualmente, nota-se no avançar das narrativas as mudanças que evidenciam a inconformidade com a realidade de discriminações que segregam o feminino e que personagens compartilham através de compreensões/interpretações de suas histórias.

As trajetórias dos personagens além de socializar e familiarizar dando visibilidade ao cotidiano, trilham o que denomino de caminho ético. Caminho este em que são evidenciadas mudanças no gerir da vida profissional, pessoal e social; encontros consigo, com os outros e com o mundo; oportunidades de singularização de sentidos à vista de agirem na correspondência que expressam;

${ }^{6}$ HEIDEGGER, 1927/2012, p.102. 
e tentativas de vigorar a humanidade que Ihes contempla constituindo seres pertencentes ao mundo.

Ao evidenciar o fundamento na Fenomenologia heideggeriana para a leitura dos clássicos literários, destaco o pensamento heideggeriano fomentando uma estreia compreensiva interessada no constituir dos elementos que anunciam femininos como provocações e não conformidades às naturalizações das relações. A Hermenêutica move-se ao lado da vida cotidiana de personagens e exercita a compreensão do ser à maneira dos humanos. A reflexão desde a Fenomenologia Hermenêutica inaugura uma proximidade com o exploratório, diferenciando-se daqueles que experimentam confirmar hipóteses. A condição de abertura a interpretações a qual somos conduzidos pela Fenomenologia Hermenêutica heideggeriana nos confronta com a circularidade que dinamiza a compreensão. Em jogo estão, segundo Heidegger7, hermenêutica e sentido movimentando-se inseparavelmente.

A Hermenêutica não é modo de ação experimental e seu anúncio garante metodologicamente uma análise. Na presente ocasião, o exercício hermenêutico é apresentado no suscitar dos modos como exercitamos a leitura dos fenômenos, ao passo que privilegia o que constitui o feminino através da literatura referida e que vem sendo comentada ao longo do texto. Evidencio que comumente as interpretações sobre o feminino sentenciam os escritos a uma ideia de feminino que necessita ser complementada pelo masculino, pela cor, pela hierarquia econômica e pelas funções sociais segregacionistas.

Na Fenomenologia Hermenêutica heideggeriana, a condição de existentes nos possibilita sermos envolvidos por sentidos, assim nossos modos de ser estão fundamentados em compreensões. Além disso, abrigamos um pré-compreender ontológico que nos possibilita desde sempre, apesar das limitações materiais e imateriais, movimentar a circularidade, compreender, investir e tomar posse de sentidos.

Conforme Heidegger ${ }^{8}$, a circularidade nos lembra que antes de interpretar, compreendemos. Antes de procurar as causas ou explicar o que acometeu

\footnotetext{
7 HEIDEGGER,1927/2012.

8 HEIDEGGER, 1927/2012.
} 
Caldeira, D. G. S., Carolina e Clarice: aproximações entre fenomenologia heideggeriana, feminino

Carolina de Jesus e Clarice Lispector compreendemos a correspondência originária que elas nos provocam. Ao corresponder, demonstramos o sensibilizar suscitado, na conformidade exposta pela Fenomenologia Hermenêutica heideggeriana, as palavras, mais do que teorizar sobre os assuntos, desvelam possibilidades aos fenômenos observados. O que faz recordar:

[...] toda relação de pergunta move-se inevitável e constantemente em círculo. Só que não é um círculo vicioso, um círculo que deveria ser evitado por ser supostamente errado. Antes, o círculo pertence à essência de todo perguntar e responder. É possível que eu já tenha um conhecimento daquilo pelo que pergunto, mas isso não quer dizer que eu já reconheça explicitamente aquilo pelo que eu pergunto, reconhecer explicitamente no sentido de ter apreendido e determinado tematicamente?

As perguntas diretas e indiretas apresentadas nos escritos literários aqui salientados expõem a materialidade das experiências, reiteradamente, materialidades enrijecidas e moldadas pelo sofrimento. Tais perguntas funcionam semelhante a instrumentos críticos das escritoras e personagens cujas respostas não são suficientes para abrandar o que sentem. Em Jesus ${ }^{10}$, a escritora interrogou-se: "Os pobres de outros lugares do mundo não poderiam sofrer tanto quanto aos brasileiros?". A questão expressa a inconformidade da escritora na ocasião em que soube da morte de um conhecido seu, esse morreu e foi enterrado pelas autoridades públicas como indigente. O conhecido que Carolina de Jesus sabia que existia, mas não poderia assegurar nome, sobrenome, registro civil ou endereço, e que horas antes de ter notícias de sua morte, a escritora presenciou-o comendo comida do lixo. Por sua vez, em Lispector ${ }^{11}$, a escritora indagou sobre sua protagonista: "teria maneira de Joana levar consigo a casa da infância?". Na sequência, a escritora comenta com os leitores que para responder esta indagação Joana necessitaria ter tecido consigo o que esta casa quer dizer, o lugar que Joana reserva à casa e que Joana se permite aceder e, mesmo assim, diante da pergunta da escritora, autora e personagem não conseguiriam garantir respostas.

Estas perguntas não são hipóteses. As narrativas apresentam em palavras a realidade por eles (escritoras e personagens) atravessadas, realidade essa cuja

\footnotetext{
9 HEIDEGGER,2009, p.69.

10 JESUS, $1960 / 2007$.

11 LISPECTOR,1943/1998.
} 
materialidade aparentemente é tão intransponível que necessita de ser dividida enquanto questão com os leitores.

O material tem lugar de destaque nas narrativas, não se trata de devanear sobre paixões ou impressões, é sobre a fome, a dor de se ver sozinha, a incerteza de encarar os dias e construir sua história sem esperar por salvadores, etc. O material desvelado nas narrativas encontra-se abrigado na percepção de que as instituições não garantem bem-estar. O material é concreto faz-se rompimento e cicatriz, sua concretude é palpável, exigente de caminhos nos quais atualizamos nossa harmonia quando exercitamos pensar-sentir-agir de forma válida como seguir regras. O material é táctil à semelhança de que escritoras e personagens constroem sentidos para forjar lugares, alcançar conquistas e inaugurar aprendizagens.

Desmesurada concretude faz impressão de que as narrativas esgotam suas forças na defesa de que existe uma condição melhor e perfeita a ser alcançada. Viver e existir se confundem. Um e outro não recaem em funções alienantes ou entorpecentes, mas acendem sentidos. O feminino não indica características ou critérios impressos por quem estagnado o observa, ao contrário, o feminino sob uma inspiração Fenomenológica heideggeriana exemplifica criação, transformação e revolução das lutas por sentidos integradores.

Os aspectos constitutivos privilegiados, na Fenomenologia heideggeriana, para análise em Quarto de desejo e Perto do coração selvagem são especialmente sentido do ser e linguagem. Admitamos sentido do ser conforme agregamos significados a todas as coisas, o que quer dizer atribuir valor, importância, apropriando-nos de um lugar. Por sua vez, sentido como o manifestar da correspondência existencial ser-com, isto é, modo de nos tornarmos humanos voltados à unidade que é nossa correspondência. Por último, a linguagem compete qualidade de deliberar, decidir, atuar desvelando significados na medida em que nos constituímos. Saliento que linguagem em Heidegger ${ }^{12}$ é modo originário, não se trata de meio ou de veículo, e sim fundamento que nos corresponde abrindo-nos à disposição e à autonomia.

Existir humanamente é tentativa de encontrar espaço-tempo, ademais as

12 HEIDEGGER, 1927/2012. 
Caldeira, D. G. S., Carolina e Clarice: aproximações entre fenomenologia heideggeriana, feminino

escritoras aqui analisadas encontraram espaço-tempo ao escrever, ao compartilhar com o mundo a insuficiência que representa se conformar com opressões, hierarquias e estigmas sociais. No resgate da Fenomenologia heideggeriana, proponho desconstruir interpretações que se sobreponham às compreensões as quais sintonizam desvelamento de experiências a fim de aceder aos sentidos; e resgatar protagonismo para o feminino sem o privilegiar de dicotomias.

O exercício compreensivo aqui desenvolvido contraria tentativas de expor uma suposta neutralidade e evidencia uma circularidade compreensiva que é envolvente a todos nós, seres-com. Compreender é ação originária sempre a ser inaugurada, e nesta ação se evidencia nossa abertura ao mundo e como estamos correspondendo. Segundo Sá13, o círculo hermenêutico heideggeriano apresenta sua cooperação no destaque às experiências atentando, permanentemente, às questões referentes aos modos como existimos. Consoante reitera Caldeira14, "esta circularidade evidencia humanamente nossa tarefa de mensageiros, enquanto viventes de nossa finitude e do viger de abertura ao horizonte de sentidos" (p. 32).

Ficam evidentes as tentativas de neutralizar e remover a positividade do feminino contrapondo-o às experiências masculinas que reiteram naturalizações de poder, domínio, superação, etc. Inclusive, quando se elege abordar protagonistas vivenciando episódios de "aparente fragilidade" a escolha dá-se, na maioria das vezes, pela reunião de características associadas ao feminino. Assim, o feminino atuaria de forma análoga a reunião de características qualificativas de sujeição, a objetivação que ameaça o feminino outorga propriedade a quem reivindica posse de vidas como se tratasse de funções. Nesta habitual ideia de feminino estariam condensadas obrigações quanto ao agir, de modo a satisfazer e atender expectativas, contrariamente a esta hegemonia se posicionam as escritoras.

Autoapresentação é outro ponto importante na compreensão do feminino descrito pelas escritoras. Nas respectivas alternâncias em que se autoapresentam sejam escritoras ou personagens, o desvio é instalado sem remeter

\footnotetext{
13 SÁ, 2017.

14 CALDEIRA, 2019.
} 
necessariamente a descrições de como operá-los. O "eu" perde noções padronizadas e instala-se o existir em conjugações do tipo: "eu sou a cada vez"; inclusive nos episódios em que existir se manifesta envolvido por objetivações, por exemplo em Jesus'15 "eu sou a fome", quanto a Lispectorl6 "eu sou uma inconformidade que não consegue apenas seguir as regras sociais (do casamento)" e "eu sou meu trabalho, minha escrita, preciso escrever para me manter viva, é o que me resta".

As autoapresentações das escritoras e personagens expõem, suportadas na Fenomenologia Hermenêutica heideggeriana, a sujeição dirigida às escritoras e aos personagens, ao mesmo tempo em que há necessidade de liderar a si mesmos. Refiro na sequência desvios construídos na literatura e que expõem reflexão/compreensão psicológica de inspiração na Fenomenologia Hermenêutica de Martin Heidegger:

Em Quarto de despejo: diário de uma favelada, a precisão de cada palavra empregue traz um aparente tom de dureza para os assuntos debatidos por Carolina de Jesus. Contudo, não acredito haver maneiras de falar sobre desigualdades, opressão e desprezo sem parecer duro ou realista, ainda mais considerando que esta escrita rompe com qualquer ideia de que Literatura serve para distração e cultivo de um romantismo alienado. A escrita deste diário faz jus a declaração de crítica e a necessidade de reflexões, são notícias da vida de pessoas que na maior parte das vezes foram esquecidas. Ao invés de consumir uma vida social, Carolina de Jesus e seus personagens doam vida ao social, oferecem empoderamento e atitude todas as vezes que não se rendem a letargia que o estado extremo de fome provoca.

Recordo uma situação descrita por Carolina de Jesus sobre o desânimo que a fome provoca, ao contrário da bebida que parece preencher e ocupar um lugar que é de satisfação, que dá motivos para cantoria. A fome, por sua vez, na sua crueza pesa, empurra para baixo ânimo, forças e pensamentos. A escritora referiu como a ação alimentar-se, rapidamente, faz as forças voltarem, não apenas força física e sim, inclusive, o entusiasmo para agir.

\footnotetext{
15 JESUS, 1960/2007.

16 LISPECTOR, 1943/1998.
} 
Não leio o diário de uma favelada subtítulo de Quarto de despejo como uma história de quem venceu pelos estudos e pela arte e/ou não soube viver em sociedade. Os personagens e a matéria-prima tematizada são expostos com a radicalidade que a arte e a educação permitem. Porém, a história demonstra que a partir da fome e da injustiça nascem modos de orientar a vida, modos de liberdade não aprisionáveis pelo capital e que, numerosas vezes, as instituições sobrepõem-se ao existir.

Além disso, em Lispector17, destaco: seria a liberdade uma propriedade humana? A protagonista Joana nos conduz a questionar sobre nossa liberdade. Joana ressalta os anseios e as abdicações que ela quer dispor como se fosse possível fazer da liberdade uma escolha.

Na liberdade como expressão autêntica de totalidade nada falta, então, por que ao nos referir a liberdade associamos escolhas ou como se se tratasse de algo que pode ser retirado? Por que relacionar a liberdade ao cerceamento do ir e vir? Em Clarice e Joana, descobrimos que mesmo quando perturbadas em seus pensamentos e comportamentos, agindo sem concordância entre pensar-agirafetar, a liberdade está a exprimir-se enquanto orientação.

A escritora não se conforma, defende o advir, o ato de se inaugurar, o tomar posse do que há dentro dela na qualidade de manifestação. Liberdade não é análoga ao reconhecer de experiências, mas admitir que experiências estão, mais ou menos, abertas para serem compreendidas e nesta compreensão expomos o que nos fundamenta. Ao admitir que Joana aprendeu a estar mais atenta ao que a fazia livre, nesta ocasião, manifesta-se a possibilidade de amar o que já ocupa um sentido nela e a acolhida para outras possibilidades as quais pareciam estar escondidas. As memórias que Clarice e Joana reativam não são, por exemplo, restritivamente sobre a conceituação da instituição família, mas do lugar que as regras presentes nesta instituição ocupam na escritora e na personagem, isto é, quais os sentidos que as conectam ao mundo a partir dos vínculos com as suas famílias. Escritora e personagem nos doam pistas a par de inventarem a liberdade de seus/nossos próprios começos. A liberdade que sob a tutela de todos nós,

17 LISPECTOR, 1943/1998. 
Caldeira, D. G. S., Carolina e Clarice: aproximações entre fenomenologia heideggeriana, feminino

acaba por ser esquecida, quase como um "destino", mobiliza a não descansarmos e permanecermos em alerta.

\section{III) Escritos de libertação do feminino}

À medida que nos deixamos contagiar pelas narrativas de Carolina de Jesus e Clarice Lispector nos aproximamos de uma liberdade que não é propriedade. Em exclusivo, não são essas escritoras que garantem a não objetivação da liberdade, ao ressaltar a Fenomenologia heideggeriana, proponho o desvelar de liberdade como existencial, isto é, enquanto modo de orientar as experiências. Neste sentido, todos os entes humanos estão lançados à possibilidade de traçar compreensões que não sentenciem a liberdade a qualquer noção de determinação ou posse.

A libertação que nomeia esta seção advém de resgatar a ideia de se autoapresentar líder de si, demonstração da posição de autoridade de suas escolhas e expressão negativa de sujeição. A totalidade daquilo que é expresso pelas escritoras vai além de determinar causas e motivações que acabariam por representar determinação e posse.

Ao se apresentarem e apresentar seus/suas personagens ao público há uma aposta, um empréstimo ao mundo daquilo que as escritoras veem, acreditam, temem e lutam, ou seja, o todo que são, conciliando o singular e o de ninguém. Conforme Heidegger ${ }^{18}$, não raras são as vezes que nos reduzimos a impropriedade de ninguém. As alternâncias entre singular e plural fazem das narrativas autoapresentações daqueles/as que não se veem conclusos. A distância entre humano e mundo são rompidas, nomeadamente quando nestes escritos são oferecidas disposições mais ou menos abertas, constâncias de se sentirem fortalecidas e vulneráveis, saudáveis e adoecidas, fazendo companhia ao mundo da vida.

Uma vez dispostas ao livre, as solicitações persistem, pois não há monotonia para quem é convocado a lutar pela vida e pela sobrevivência, outrossim, é solicitado a encontrar sentido aos dias. Aos convocados e solicitados, isto é, autores de suas histórias reais ou fictícias, o trabalho persiste não por resposta ou

18 HEIDEGGER, 1981. 
solução definitiva, mas se dispõe no enfrentamento por encontrar lugar para si e espaço-tempo de satisfação consigo e com os demais. Não se trata de aversão ao masculino, mas sinalização ao mundo de que humano é todo aquele/a, homem e mulher, preparados/as ou não, construtores de valores, histórias e esperanças.

O feminino não é um lado, muito menos, um lado destituído de liberdade. No feminino, apesar do convívio com manejos seus ou alheios preenchidos de opressão, permanece compondo mundo e se refazendo a partir de sentidos convergentes de interpretações e compreensões.

Libertação do feminino expressa o dialogar com o corpo que habitamos; descobertas, aceitações e desentendimentos, pois ao mesmo tempo habitar e corresponder não são alternativas. Há na pluralidade de femininos, nas maneiras de reconstruir relação humano-mundo, ideologias de supremacia do masculino legitimadas por discurso de origem da vida, conforme Butler ${ }^{19}$, ou sobre pecado original, segundo Toldy20. Discursos como estes segregam o feminino a papel secundário inferiorizando, impondo e negando possibilidades.

Libertar o feminino é sinônimo de rompimento com ideologias e crenças que homens e mulheres se encontram envolvidos e segregados. Destaco três rompimentos inadiáveis:

Primeiro, romper com a ratificação de naturalidade do feminino que, na maior parte das vezes, o apresenta como insignificante cujos representantes são igualados em vulnerabilidade, pensamentos emotivos e ações impulsivas. Segundo, desfazer complementaridades, por exemplo, nada falta ao feminino uma vez que seu projeto existencial não se resume a procurar por algo, não há feminino que procura masculino, semelhante a alguém que procura a salvação. Terceiro, questionar o sujeito psicológico que frequentemente é representado por um eu masculino, exemplifico: o "eu" nas autoras é a pessoa que contém todas as outras, um "eu" que não segrega, ao contrário doa voz, anuncia notícias ao mundo que vigoram ações, sentimentos e inquietações em todos os entes humanos.

\footnotetext{
19 BUTLER, 2003.

20 TOLDY, 1998.
} 
Libertação do feminino não aparece como espécie de lugar que the é endereçado a ocupar, e sim advém da importância do valor que circunda as suas experiências entre compreender e posicionar. Ao feminino repousa uma polissemia inquieta cujas explicações são rasas diante de sua profundidade, o que the pertence em profundidade é compreender como quem corresponde. Todos correspondemos, advimos não apenas da mulher biológica, mas inclusive do feminino.

A radicalidade do feminino une as duas escritoras nas alternativas em que cada uma sutura entre seus modos de existir e ações cotidianas. Resistir como elas e seus personagens fazem ao passo que compartilham anseios, demonstra-se um convite a atentarmos aos valores do humano que representam e que estamos todos contaminados, por exemplo, patriarcado, racismo, etc. Libertação do feminino dá-se como ato de resistência, distancia-se de apostar forças na ânsia de extinguir o que faz sofrer, é redirecionar o que se mostra hegemônico a fim de mobilizar alternativas. Através das autoras e personagens não recaem ou são propostas soluções, por exemplo, imaginar um dia em que não precisariam se reafirmar. Utopias como a exemplificada são precárias. Habitar no feminino liberto não é trabalhar pelo suficiente extrapola seguir regras é decidir avançar, voltar atrás e cultivar a cada vez.

Na defesa pela elucidação de compreensões nos tornamos livres em proveito de manejarmos com nossos limites humanos, conciliando restrições e alargamentos de possibilidades. Comumente, a ciência e profissão da Psicologia contemporânea aborda questões do existir humano como se tratasse de uma característica do homem abrigada no interior de mente, da cognição, do self e com isto agravamos nossa situação, pois naturalizamos segregação humanomundo.

Liberdade para a Fenomenologia heideggeriana promove a libertação do ente humano enquanto guarda de sua verdade. Neste sentido, encontramos na compreensão da liberdade um exercício ético suportado na Fenomenologia heideggeriana e expressivo da modalidade de nossa humanidade. Na conferência Ontologia, Hermenêutica da facticidade, Heidegger ${ }^{21}$, o filósofo trouxe

21 HEIDEGGER, 1923/1995. 
Caldeira, D. G. S., Carolina e Clarice: aproximações entre fenomenologia heideggeriana, feminino

o tema liberdade real, essa liberdade não dizia respeito à indiferença, uma vez que se relacionava a autointerpretação do Dasein. Heidegger rompeu com a tradição de abordar a liberdade e apresentou-a na condição de modo de pensar. Assim, o ato de pensar inauguraria variados delineamentos de liberdade, libertações da liberdade; liberdade expressa quanto às possibilidades humanas e às correspondências humano e mundo.

Nota-se em Heidegger22, que liberdade consoante essência da verdade proporciona o desencobrimento mais originário, sem dependências, isto é, sem vontades, uma disposição do próprio possibilitar, exercício de devir construindo seu próprio caminho.

Em Ser e tempo, liberdade existencial possibilita expressão do fundamento remetida à necessidade de entregar $\circ$ fundamento que é $O$ existir, designadamente o existencial liberdade guardando o ente humano. A temática da liberdade, a partir do panorama heideggeriano, é questão fundamental e, portanto, não há meios de manejá-la como representação de algo fáctico. No parágrafo 31 de Ser e tempo, o filósofo aproximov o caráter existencial da afinação e da disposição na compreensão do ser no fundamento do existir, assim resgato para a leitura da liberdade presente nos clássicos da literatura. Soa na liberdade existencial modificações à disposição e acessibilidade pela facticidade. Conforme Caldeira23, "a facticidade nos doa pistas considerando acompanharmos o deixar ser outro que constitui a afinação fundamental de nossa correspondência ser-uns-

\section{com-os-outros".}

Neste deixar ser outro, liberdade exprime-se possibilidade existencial e libertação presentes em nós pela facticidade humana. Para Heidegger24: "liberdade nada tem a ver com causalidade. A liberdade é ser livre e aberto para uma solicitação". Liberdade expressa nossos modos de ser cotidianamente. Visto que no desvelar dos fenômenos em Heidegger25, a liberdade (Gewissen) provém da facticidade de nosso existir, pois somos remetidos àquilo que nos é possível frente à nossa disposição e consciência diariamente.

\footnotetext{
22 HEIDEGGER, 1979.

23 CALDEIRA, 2019, p. 163, (grifos da autora).

24 HEIDEGGER, 2009, p. 256.

25 HEIDEGGER, 1927/2012.
} 
Liberdade não poderia ser simplificada como representação ou propriedade humana, uma vez que se apresenta possibilidade, caminho que nos conduz ao que estamos mais ou menos dispostos na qualidade de fundamento. Nossas tentativas de restringir, definindo liberdade, são superficiais. Para Gikovate26, envolvemo-nos inclinados, quase que atraídos pelo significado que designa ser livre, apesar de desconhecermos sua definição.

O modo usual como a Psicologia aborda o tema da liberdade humana distancia-se da liberdade fenomenológica. No final do século XIX, Henri Bergson (1859-1941) defendeu a liberdade como problema central da Psicologia científica. A principal questão que Bergson ${ }^{27}$ se interessou foi a equiparação da liberdade tratada às voltas do plano do livre arbítrio. Com isto, há uma espécie de distorção das experiências de liberdade por nos mantermos presos não à experiência, mas à estrutura simbólica da linguagem. Essa distorção expõe a restrição da ciência e de seus profissionais em tentar decodificar símbolos, admito que liberdade é composta de estrutura simbólica, porém liberdade manifesta-se em ação e não está à espera que alguém ou algo venha a desvendá-la.

Liberdade enquanto prática não expressa determinismo, consoante Heidegger ${ }^{28}$, "[...] a questão acerca da essência da liberdade humana não pode ser nenhuma questão científica". Dado que liberdade escapa aos critérios científicos que não sejam voltados a decodificar a sua estrutura simbólica, temos na liberdade existencial um horizonte que como constitutivo dos entes humanos nos faz singulares, pois rege nossos modos de ser.

$\mathrm{Na}$ condição de entes humanos, experimentando as questões da liberdade compomos sentidos que as possibilitam, portanto, nos apropriamos de nossa condição de projeto. Apropriação não tem relação com esgotar possibilidades na procura pela representação mais autêntica. A facticidade que é expressão de correspondência com nossos percursos, envolvendo disposição e afinação, constrói nossos ritmos e posicionamentos.

A influência da Fenomenologia heideggeriana auxilia compreendermos psicologicamente que a liberdade humana não é, por exemplo, um feito voltado

\footnotetext{
26 GIKOVATE, 2000/2006.

27 BERGSON, $1927 / 1988$.

28 HEIDEGGER, 2012, p. 22-23.
} 
Caldeira, D. G. S., Carolina e Clarice: aproximações entre fenomenologia heideggeriana, feminino

a definir o que seja liberdade para escritoras e personagens investigados. Portanto, compreender psicologicamente demonstra-se, considerando experiências cotidianas e literárias, evidenciar possibilidades de liberdade ao passo que somos tomadas pela liberdade que nos fundamenta. O mais relevante é apoiar uma apropriação do ente humano quanto aos seus caminhos, unidamente, destacar o zelo de nossas correspondências, como é verificável nos clássicos literários citados. Nesta lógica, Heidegger dialoga com os clássicos citados recordando-nos:

Liberdade humana é a liberdade, na medida em que ela irrompe no homem e o toma para si, possibilitando-o por meio daí. Se a liberdade é o fundamento da possibilidade do ser-aí, a raiz de ser e tempo e, com isso, o fundamento da possibilitação da compreensão de ser em toda a sua amplitude e plenitude, então o homem é, fundando-se em sua existência e nessa liberdade, aquele sítio e ocasião, na qual e com a qual o ente na totalidade se torna manifesto, e aquele ente, por meio do qual fala o ente na totalidade enquanto tal e, assim, se enuncia ${ }^{29}$.

Somos livres para reger sentidos e escolhas seja expressando ética, seja na defesa pela não segregação do feminino, assim permaneceremos conciliando o ser sensível e ser racional, uma vez que conforme Heidegger ${ }^{30}$, em liberdade estamos na condição de possibilidade que é compreensão do ser. Os sentidos para afinarmos a liberdade manifestam-se no promover de encontros ao passo que admitimos nosso poder-ser.

\section{IV) Uma Fenomenologia Hermenêutica do feminino como resistência, modo ético de experienciar}

Um novo entendimento de humano não restritivo à ideia de humano restrito a homem, heterossexual e capitalista não é concepção alheia ao nosso cotidiano.

As escritoras demonstraram que o feminino não é inserido na linguagem literária como uma espécie de supervalorização. Logo, o feminino se autoapresenta como criação, cria oportunidades e caminhos, inclusive concebe as amarras e seus limites. Justamente, onde se cria não é compaginável a conformidade com opressão, controle e segregação. Nesta seção, a Fenomenologia heideggeriana que vem inspirando compreensões ao tema, após

\footnotetext{
29 HEIDEGGER, 2012, p. 163, (grifos do autor).

30 HEIDEGGER, 2012.
} 
seção de exposição de diálogo feminino e liberdade, demonstrar-se-á um mergulho na proposição de que feminino é designadamente um modo de resistência, frente aos entraves que camuflam o protagonismo do feminino. Consoante referido, a partir de padrões metodológicos científicos são adotados sobrenomes para referir autores e autoras, contudo este critério acaba culturalmente e não só, por invisibilizar a quem pertence a autoria. Reitero a decisão de aludir as escritoras por seus nomes e não, exclusivamente, por seus sobrenomes acreditando mobilizar validade ao conhecimento e à sensibilidade dessas mulheres.

Apropriar seres humanos dos seus lugares vai além de dizer que o feminino se reserva a isto ou a aquilo. Apropriar enquanto superação não dispersa forças, ao contrário concentra-as, empodera-as de reflexões, ações e compreensões que são demonstrativos de liberdade.

A presente proposta de compreensão Fenomenológica Hermenêutica do feminino, nos clássicos literários referidos, é uma tentativa de contribuir para o resgate da noção de feminino e, não apenas, inclui cuidar do humano que somos. Compreensão simultânea às vidas, às histórias e às personagens que se vão fortalecendo na medida em que as narrativas contactam leitores/as é maneira de explicitar aquilo que, muitas vezes, exercemos como se estivéssemos distantes uns dos outros, como se tratasse de vontade ou querer humano.

Para a presente leitura do feminino, as possibilidades ao ente humano seja homem ou mulher manifestam-se abertura ao fundamento, consoante Heidegger ${ }^{31}$. Na presente compreensão, defendo feminino envolvido em contextos relacionais e de possibilidades. Nestas dinâmicas, o feminino não escapa à normatividade, contudo na libertação do feminino que a leitura fenomenológica heideggeriana possibilita é necessário considerar a normatividade e agir entre tentativas de representação, pois o principal é estarmos atentos aos modos de gerir o feminino, para ao invés de ser desvio não o transformar em categoria.

Estratégias de resistência do feminino não são alcançáveis no desviar de enfrentamentos e sim reiterando atenção ao suportar considerações às raízes que fundam e às escolhas realizadas que em lugar de fazer crescer, podam. Podas que

31 HEIDEGGER, 1979. 
nos privam, não como quem poda para potencializar, está mais ao estilo daquelas podas que se empenham em conter de maneira que nada nasça, floresça ou frutifique para além das margens estabelecidas.

Pensar, como estratégia incentivada ao longo do espólio heideggeriano, caminha na temática do feminino ao lado do agir sereno e providencialmente, sereno no sentido de quem pensa/reflete, semelhante a temática da conferência Serenidade. Nesta ocasião, Heidegger ${ }^{32}$, contraria a concepção de humanos acostumados a valorizar a razão que calcula e que se esquiva das possibilidades. No pensar como estratégia é providencial questionar o feminino como quem traz vida e mantém em seu horizonte as correspondências humano-mundo, sem negligenciar ou menosprezar o desdobramento dos posicionamentos.

Cuidar do feminino pela via da compreensão é construir novas resistências, admitir erros, conquistas e tracejar direções éticas envolvidas com o primar pela coerência de não destituir e segregar entes ou ampliar distâncias. Questionar o feminino sobre si, cuidá-lo naquilo que pode ser melhor, é mais coerente com o viver e não apenas com o seguir de regras. Aquilo que respondemos no questionamento sobre o feminino são expressões do nosso habitar humano, nestas respostas ou constatações impregnamos nossas forças e nossos esforços. Movimentar-nos entre categorias é trabalhar para que conceitos não aumentem o fosso entre os modos de vivermos e aquilo que nos constitui humanos. Feminino, racismo e injustiças não são símbolos parados à espera de interpretações, mais significativas são as suas variantes atingíveis a todos e que a Literatura nos contempla expressando as manobras da vida e o manobrar dos personagens.

Acompanhar o desconforto dos personagens mobiliza-nos como experiências que poderiam ser de qualquer um, contudo cotidianamente é mais difícil vislumbrar saídas, interromper inquietações, visto que não há apenas páginas ou capítulos a serem ultrapassados. As lentes que o saber psicológico me empresta são companhia, contudo não me apropriam da realidade, uma vez que realidades estão sendo geridas pela primazia do discurso verbalizado ou não. A mediação com as experiências que a Fenomenologia Hermenêutica possibilita não traz conclusões, todavia conduz mediações na construção de humanos que

32 HEIDEGGER, 1959/2001. 
percorrem seus horizontes. Negar horizontes é negar humanidade que diz respeito a mulheres e homens, meninas e meninos. No humanizar tomamos decisões, negálas é forma de endurecimento, exaurir as correspondências, um acentuar das distrações que colaboram para nos afastar do autoconhecimento e de autoapresentação componentes do exercício de sermos éticos.

A ética filosófica, inserida na Filosofia Moral, pela via da razão dedica-se à dimensão moral humana, apesar de não ter optado por este caminho para defender ética nos modos como contacto escritoras e escritos evidencio que ética filosófica e ética inspirada na Fenomenologia heideggeriana trabalham na tentativa de evitar totalizações, espécie de versões rígidas do que seriam os valores humanos e como são experimentados.

A Ontologia Fundamental de Martin Heidegger possibilita inspiração para ética, partindo da nossa condição de ser-no-mundo, considerando a ambiguidade convergente à nossa condição de morais e existentes. Por ética, admitindo-a ethos é maneira de compartilhar o repouso aberto à nossa morada existencial. Não apenas raciocinar sobre ética, inclusive meditar enquanto modo de pensar se revela nos abrir a possibilidade de manifestação daquilo que somos, nossas crenças, daquilo que conseguimos operar, ajustar e nos refugiar. As influências da Metafísica presentificam-se na atualidade na vigência das ciências em nosso cotidiano. Análogo exponho, o que Heidegger nos convida a pensar sobre ética ou sobre o feminino repousa em contactar modos como somos, agimos e nos afetamos; quanto aos fenômenos a exemplo do feminino, manifestamente críticos às influências Metafísicas em nosso dia a dia, exemplificam tentativas de averiguar, adoções de medidas prévias de como agir e pensar.

O saber psicológico contando com a inspiração da Ontologia Fundamental e o método fenomenológico constrói estratégias para auxiliar neste repouso na ética, na qualidade de ethos de quem não conta com medidas prévias, como se estas garantissem verdades. Como vimos, verdade e liberdade, no sentido existencial abdicam de voluntarismos, no caso de voluntarismos psíquicos que expõem na maioria das vezes necessidades e não como somos, como correspondemos enquanto constituintes e constitutivos de mundo. As ciências, a exemplo da Psicologia e os humanismos, garantem ao ente humano um lugar 
Caldeira, D. G. S., Carolina e Clarice: aproximações entre fenomenologia heideggeriana, feminino

central e de tanto privilegiar este lugar deixamos escapar que não há segregação humano-mundo, muito menos, existem alguns humanos em condição superior aos demais.

Nossas manifestações de como somos e vivemos não resumem os fenômenos em si, conforme exposto em Heidegger 33 , o filósofo destacou que pensar o fenômeno quando este se mostra é diferente de pensar sua manifestação. Nossas manifestações são ocasiões privilegiadas para nos aproximarmos da compreensão do caminho que estamos percorrendo, na medida em que estamos deambulando, só assim o sentido que se imprime e se evidencia por uma clareira que nem sempre expõe o que queríamos ver, e que nem sempre encaixa dentro das categorias prévias que nos cercamos.

Ética, liberdade e feminino manifestam nos escritos citados e no cotidiano, enfrentamentos ou constatações da finitude. O que não quer dizer que ética, liberdade e feminino sejam finitude, contudo lembremos que diante das restrições do existir que a finitude imprime frequentemente nos questionamos sobre quem somos. E ao sermos, cabe perguntar: "como estamos sendo?". Carolina de Jesus e Clarice Lispector enfrentaram estas perguntas por motivos diferentes. Para a primeira adveio com a pobreza e a precariedade, e para a segunda ocorreu diante da instabilidade das possibilidades de viver consigo e socialmente, por exemplo, no gerir a vida e a liberdade que the pedem vazão, e ela não sabe como proceder.

Nas autoras o resistir que o feminino provoca repercute em perseveranças simbolizadas, por exemplo, em ter atenção, escancarar seus limites, admitir suas fugas e incompletudes. Não quer dizer que ao fenômeno do feminino se associam apenas sofrimentos, adoecimentos e declinação da jovialidade. Estes eventos ocorrem, todavia, os limites servem igualmente quase que as transformando e as suas personagens em imortais. A dureza desta constatação está no ato de Carolina e Clarice ao escreverem sobre condições de vida nos permitirem mudar nosso modo de nos pensarmos e ao mundo, tal e qual se permitiram. As escritoras anunciaram um futuro ainda no tempo presente, como um futuro que germina. Vigorar ética, resistir através da libertação do feminino é inclusive isso, anunciar um

33 HEIDEGGER, 1927/2012. 
Caldeira, D. G. S., Carolina e Clarice: aproximações entre fenomenologia heideggeriana, feminino

futuro, que vai além de saber bom ou ruim, feminino ou masculino, cinge saudar a necessária tarefa de cuidar.

\section{Considerações possíveis}

Apropriar o humano do poder-ser que cabe somente a ele não é tarefa conclusiva, está mais para o inaugurar de novas versões.

A Fenomenologia Hermenêutica heideggeriana que inspirou a leitura reflexiva e compreensiva de sentidos destes clássicos auxilia a autocompreensão dos modos de vida ali representados, mas isto não quer dizer encontrar resposta definitiva, e sim encontrar meios de fazer-se sentir e sentido. Com este trabalho ofereço mais um passo de libertação rumo à constante emancipação (rumo ao desvio), ao empoderamento do rompimento de dicotomias simplistas que reduzem o valor dos enfrentamentos a ódios e opressões.

\section{Referências}

BERGSON, Henry. Ensaio sobre os dados imediatos da consciência (J. S. Gama, Trad.). Lisboa: Edições 70. (Texto original publicado em 1927), 1988.

BUTLER, Judith. Problemas de gênero. Feminismo e subversão da identidade. Rio de Janeiro: Civilização Brasileira, 2003.

CALDEIRA, Danielle de Gois Santos. A questão da ética na psicoterapia: contribuições da Fenomenologia Hermenêutica de Martin Heidegger. 2019. $281 \mathrm{f}$. Tese (Doutorado em Psicologia) - Centro de Ciências Humanas, Letras e Artes, Universidade Federal do Rio Grande do Norte, Natal, 2019. Recuperado de https://repositorio.ufrn.br/jspui/handle/123456789/27358

GADAMER, Hans-George. Verdade e método. Petrópolis: Editora Vozes, 1997.

GIKOVATE, Flávio. A liberdade possível. São Paulo: MG Editores, 2006. (Texto original publicado em 2000).

HEIDEGGER, Martin. Sobre a essência da verdade. In M. Heidegger. Conferências e escritos filosóficos. (E. Stein, Trad.). São Paulo: Abril Cultural, 1979.

HEIDEGGER, Martin. Todos nós... ninguém: um enfoque fenomenológico do social. (D. M. Criteli, Trad.). São Paulo: Moraes, 1981. 
Caldeira, D. G. S., Carolina e Clarice: aproximações entre fenomenologia heideggeriana, feminino e literatura. ODEERE, v. 6, n. 01, jan./jun., p. 233-256, 2021. https://doi.org/10.22481/odeere.v6i01.7870

HEIDEGGER, Martin. Ontologia: Hermenêutica da facticidade. (R. Kirchner, Trad.). Petrópolis: Editora Vozes, 1995. (Texto original publicado em 1923).

HEIDEGGER, Martin. Seminário de Zollikon. (M. Boss, Ed., M. F. de Almeida Prado, Trad.). Petrópolis/Bragança Paulista: Vozes/ Editora Universitária São Francisco, 2009. (Texto original publicado em 1987).

HEIDEGGER, Martin. Serenidade. Lisboa: Instituto Piaget, 2001. (Texto original publicado em 1959).

HEIDEGGER, Martin. Os conceitos fundamentais da metafísica: mundo, finitude, solidão ( $2^{a}$ ed., M. A. Casanova, Trad.). Rio de Janeiro: Editora Forense Universitária, 2011.

HEIDEGGER, Martin. A essência da liberdade humana: introdução à filosofia $\left(1^{a} \mathrm{ed}\right.$., M. A. Casanova, Trad.). Rio de Janeiro: Editora Via Veritá, 2012.

HEIDEGGER, Martin. Ser e tempo. (F. Castilho, Trad.). Petrópolis/Campinas: Editora Vozes/ Editora Unicamp, 2012. (Texto original publicado em 1927).

JESUS, Carolina Maria de. Quarto de despejo: Diário de uma favelada. $9^{a}$ ed. São Paulo: Editora Ática, 2007. (Texto original publicado em 1960).

LISPECTOR, Clarice. Perto do coração selvagem. Rio de Janeiro: Rocco, 1998. (Texto original publicado em 1943).

SÁ, Roberto Novaes. de. Para além da técnica: ensaios fenomenológicos sobre psicoterapia, atenção e cuidado. Rio de Janeiro: Editora Via Veritá, 2017.

TOLDY, Teresa Martinho. Deus e a Palavra de Deus na Teologia Feminista. Lisboa: Ed. Paulinas, 1998.

TRIBLE, Phyllis. Depatriarchalizing in Biblical Interpretation. Journal of the American Academy of Religion, 42, p. 42-48, 1973. Recuperado de https://www.jstor.org/stable/1461386

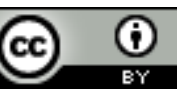

This work is licensed under a Licence Creative Commons Attribution 4.0 International (c) (i)

Este trabalho está licenciado com uma Licença Creative Commons - Atribuição 4.0 Internacional. 